\title{
CULTURE-LED URBAN DEVELOPMENT INITIATIVE IN A WORLD HERITAGE CITY: THE CASE STUDY OF THE OLD CITY OF DAMASCUS IN SYRIA
}

\author{
R.Aboukhater ${ }^{1, *}$ \\ Damascus University, Faculty of Architecture, and Institut français du Proche-Orient (Ifpo), Damascus, Syria - \\ roula.aboukhater@hotmail.com
}

Commission II - WG II/8

KEY WORDS: Cultural quarter, Traditional houses, Heritage management, Socio-economic development, Tourism

\begin{abstract}
:
This paper deals with the process of transformation of a cultural quarter developed at al-Amin district inside the Old City of Damascus. In 2006, approximately 25-30 artists, moved to this historical neighbourhood and settled in its traditional houses, changing their function into studios/ateliers. One year later, the district was called "The Artists' Quarter" with the acknowledgment of local and international institutions. The presence of artists' studios and many cultural events in the area has contributed to the discovery of the rich architectural and cultural heritage of the neighbourhood and the development of a new sphere of public encounters. This quarter became a destination for tourists as well as for locals. Unfortunately, during the war in Syria, started in 2011, different negative changes have happened at al-Amin district. The study aims to (1) Highlight the origin and development of the quarter from the point of view of the artists and the dwellers; (2) Study the spatial and socio-economic effects caused by the "Artists' Quarter"; (3) Evaluate the changes in the traditional houses due to change of their function; (4) Investigate the actual situation due to the war. Information was collected mainly from interviews with several artists, with hotels' managers and shopkeepers in the quarter, in addition to literature review, consultation of maps and plans and on-site observation. Results of the study will help in understanding this model of urban development and try to set up recommendations for integrated development and heritage management of this neighbourhood.
\end{abstract}

\section{INTRODUCTION}

\subsection{Culture, Art, and Development}

Culture has a tangible and intangible role in the enhancement of the quality of life of a city. It is more and more an essential element of a city's competitiveness in the globalizing world. The use of culture and art as a source of development and urban renewal is a highly recommended strategy for urban regeneration. "Many cities are now attempting to stimulate and encourage their citizens by promoting creativity in arts \& culture and encouraging innovation in various areas to revive their economies." (Sasaki, 2004). At the outer reaches of art and culture, there is an entire cycle and a chain of economic activities, called creative industries, which concern the amplification and creation of cultural content, without forgetting that culture has become a major attraction for urban tourism.

City centres are ideal places for cultural production and consumption. Artists often prefer to be in the city centre, but the rising prices of property lead them to choose their studios in areas that not receiving much attention from investors or developers. As they move in and settle in these locations, they accelerate the transformation of the neighbourhood and usually are followed by galleries, hotels, cafes and restaurants. Then these districts become attractive destinations for young generation and for tourists.

The strategy that includes combining cultural activities with cultural institutions such as art galleries, museums, exhibitions or others is a shift from merely organizing temporary events to a policy aimed at creating spaces of creativity and cultural production and consumption. But it may also include entire quarter or networks of locations. Galleries gathering within a cluster forming network could benefit from shared resources and a shared image.

Cultural quarters are often seen as part of a larger strategy integrating cultural and economic development. This is usually linked to the redevelopment or regeneration of a selected inner urban area, in which mixed-use urban development is to be encouraged and the public realm is to be reconfigured (Montgomery, 2003).

Cultural quarters are present in different cities in the world, as the district of Montmartre in Paris, SoHo in Manhattan in New York, the art district in east London, or Titanic Quarter in Belfast. Successful cultural quarter's models usually are based on local context that decision makers take in consideration the development plan of cities. Each city has its own unique culture that associates the distinctive heritage of the community and the aspiration for the future. Creating cultural quarters can be an urban strategy to reveal the characteristics of local identity and to improve the image of the city. In return, this mechanism would encourage economic development and create new touristic destinations.

This paper focuses on the case study of al-Amin district, providing a critical analysis of the process of transformation of a cultural quarter inside the Old City of Damascus. It explores the origin of creation of the Artists' Quarter and discusses the physical and socio-economic changes that have taken place there. It also examines the influence of the artists and

\footnotetext{
* Corresponding author
} 
stakeholders to overcome the decline in this historic quarter and to what extent it is turned to be a visitor destination. The paper notes an absence of up-down plans for using culture as a tool for developing urban areas in Damascus. It helps to draw attention to the local context of the district and its identity, which allows assuring its sustainable development in the future.

\subsection{Methodology}

The paper is focused mainly on the origin of the Artists' Quarter and the transformation of al-Amin district in the period till 2011. The general situation resulted of the war in Syria will be briefly presented. The analysis of this zone and the shift from a residential district to a cultural and touristic one, may contribute to clarify some points in the possibility of achieving this type of projects in other areas in the city or in drawing up plans for the future cultural development of the neighbourhood from social and economic aspects. On the other hand, this paper does not discuss the mechanisms that could be used by local government to associate cultural strategies in their urban development projects.

The research strategy relies on qualitative analysis and the use of a case study to exanimate the role of culture in urban development. The empirical research was carried out through a number of semi-structured interviews with several artists in the district and with some stakeholders that are key players or have played a part in the creation of the Artists' Quarter and those participated in the economic regeneration of this area. These interviews were conducted mainly over February to May $2010^{1}$ and later few interviews in December 2019. Main themes were chosen to be subjects of discussion in the interviews such as the origin of the artists' quarter, the transformations occurred in the quarter, the connection between tourism and cultural quarter designation, and the projects implemented or programmed by local authorities. Interviews were recorded, transcribed and analyzed using those main themes.

Literature review of documents dealing with models and origin of cultural quarter has clarified the role of arts and culture as catalysts for urban regeneration. Information on the physical situation of buildings between 2006 -2009 was collected from maps produced by the Municipal Administration Modernization (MAM) project. On site observation and survey in 2010 helped to identify the process of creation of the Artists' Quarter and the transformation of functions in some of Damascene traditional houses in this intramuros district.

\section{THE CASE STUDY OF AL-AMIN DISTRICT, OLD CITY OF DAMASCUS}

\subsection{Description of the District}

The Old City of Damascus, surrounded by the ancient wall, has plenty of historical monuments and vast traditional houses that are inserted in its organic urban structure. It has been recognized by the UNESCO as a World Cultural Heritage Site in 1979. Many efforts have been undertaken since the listing to ensure the protection of its urban and architectural heritage.

Al-Amin district represents a large part of the real estate of the Old City of Damascus. It is located in its south east part (Figure 1), delimited to its south by the southern wall of the city, and to its north by the Via Recta or Medhat Pasha Street, a touristic market specializing in selling different sorts of local

\footnotetext{
1 Within the framework of the Project "Cultural Participation for Heritage Regeneration" financed by the European Union and coordinated by Institut français du Proche-Orient, Ifpo.
}

merchandises and traditional handmade objects (Figure 2). On this street, a small garden, al Qeshla, is located at the corner of a major road, Tell al Hejara lane, leading to the heart of the neighbourhood. The quarter borders on the south are adjacent to the only vast green field inside the wall, the Sukkar garden.

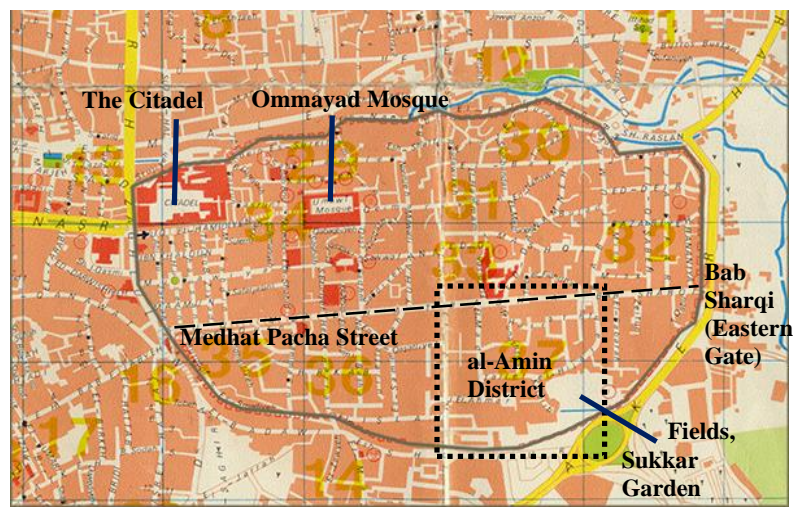

Figure 1. Location of al-Amin district in the Old City of Damascus, Touristic map, Archive IFPO.

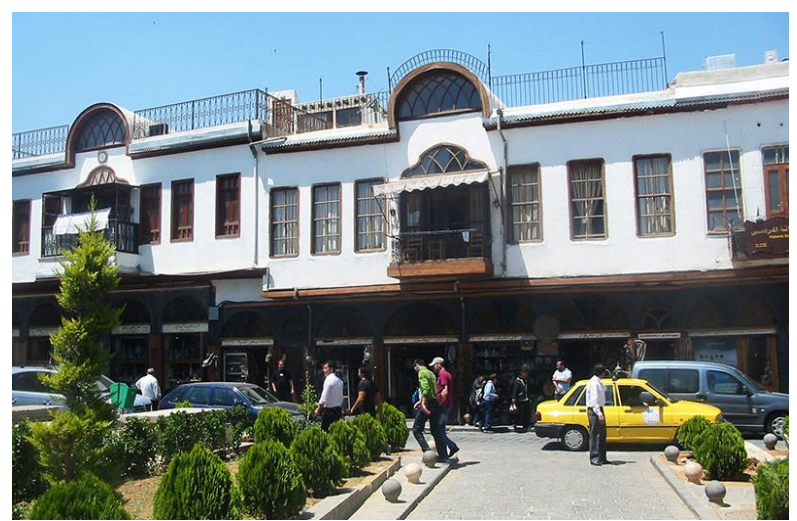

Figure 2. Shops on Medhat Pacha Street, R.Aboukhater, April 2010.

The researcher D. Sack explained in her book ${ }^{2}$ on the historical urban development of Damascus (Sack, 1989), that the pattern and the type of buildings prevailing in the south-eastern part of the neighbourhood at al Antoushi lane is rural in general, due to the continued existence of fields (Figure 3).

In the 18th century, Damascus witnessed the rule of the prosperous al Azem family. Luxury houses and palaces were built at al-Amin district as many families living there were working in trade. The neighbourhood was known and famous for several traditional crafts, as copper carving filled with threads of silver.

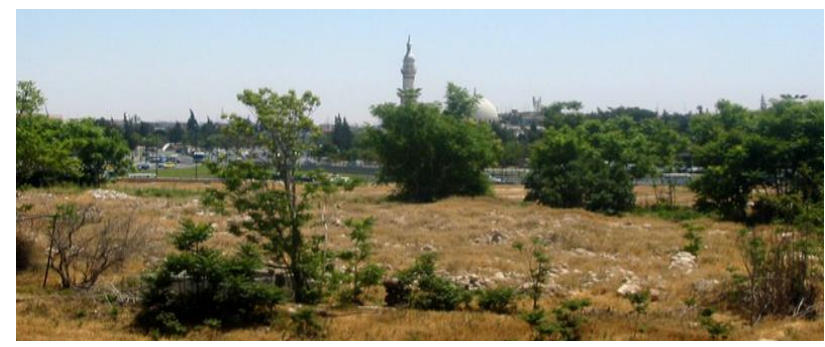

Figure 3. The Sukkar garden, R.Aboukhater, May 2010.

\footnotetext{
${ }^{2}$ Translated to Arabic, Toyer, K. 2005. Dimashq, Tatwor wa Bunyan Madina Mashriqiyya Islamiyya. Ifpo.
} 
In the western part of the district, there are a number of palaces which represent the wealth and prosper time, like the "Farhi Dahdah" house, the palace of "Shamaaia", the house of "Farhi Moualem", "Niado" house and" Shattah" house. Most of these Damascene traditional houses are abandoned or rented, and that led to the physical deterioration of most of them. About $60 \%$ of houses are in bad condition as reported by the study of problems in the Old City by MAM project (Figure 4).

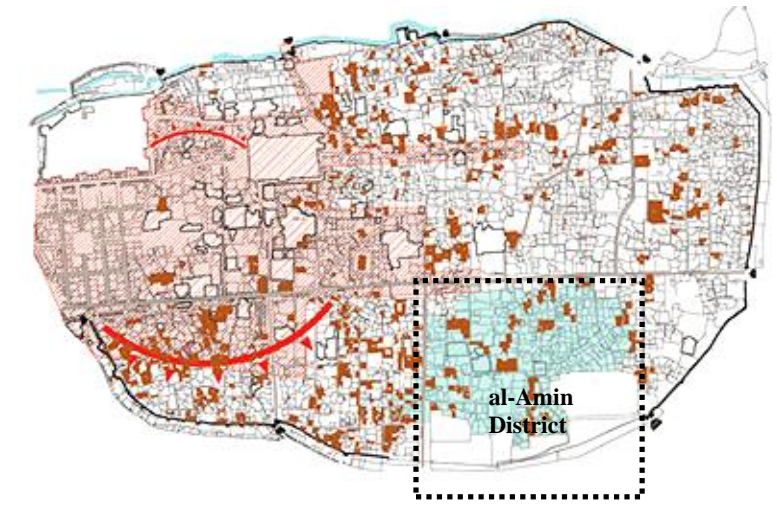

Figure 4. Plan of problems in the Old City, MAM project, 2008.

\subsection{Origin of the Artists' Quarter}

Cultural clusters or quarters are parts of several urban regeneration projects in declined urban areas in developed countries. However, the notion of cultural quarter as a key model in revitalization projects has not been applied in developed cities in spite of the remarkable cultural backgrounds and cultural heritage they have. Damascus is the oldest still inhabited capital of the world and many civilizations have passed on this land. Nevertheless, its cultural assets have not been invested and employed as they should have been.

In the 90's, an interesting experience of such clusters was the gathering of artists in a vast traditional house, at al Sibai house, in the Old City of Damascus. This house was expropriated and then restored by the Governorate of Damascus. It provided studios and workplaces for several famous Syrian artists who worked there for about two years; 1998 -1999, but this experience was stopped for several administrative reasons.

Back to 1970, another similar example is the gathering of artisans and artists (glass blowing, Damascene textile weaving, copper carving, etc.) in stores at al-Takiyya al-Sulaymaniyya, a historical Ottoman Complex, designed by the famous architect Sinan in 1566. It is located at the city centre near the National Museum and the University of Damascus. The building of the Madrasa, ancient religious school, has been managed by the Ministry of Tourism to accommodate workplaces for artisans around a vast courtyard. This helped them to show their work and to communicate with visitors who visit this historical monument and to sell their products. It is a place for production and consumption of traditional crafts. The courtyard has been appropriated by the artisans, the local visitors and tourists as a meeting point and a social place. Recently in 2013, new shops for traditional products were opened which permitted to enforce economic development.

In 1998, the artist Fadi Yazajy had the first studio at al-Amin district, where he bought a traditional house in an auction. There was no intention for him to settle in this area in particular, but he visited the neighbourhood and found it an ideal place despite the bad physical situation of the house. The emergence of the Artists' Quarter at al-Amin district was the result of an individual initiative and a futuristic idea. Mustafa Ali, a well known Syrian sculptor, was looking for a big traditional house to make it his studio, in order to expose his works as well as other artists' works. His intention was to establish an art institution to take care of art and cultural projects to create a sort of art trade between Syria and the rest of the world to support Syrian young artists. This project was not the result of top-down planning, but rather an attempt to mimic practices that occurred elsewhere, which the artist experienced them very well, by himself, during his travel around the world.

In 2003, looking for the right place, Mustafa Ali visited al-Amin district. He found a house with the criteria he wanted, as the location was perfect; it is in the Old City and the price was acceptable. The artist visited the area several times and he realized that the neighbourhood was nearly abandoned, day and night, and no one goes there, even the residents of the nearby quarters. For the above reasons, he found these conditions an opportunity to create what he thought is important for the future of the Syrian art; to create a cultural association that helps to enrich the local creative artistic economy and to deliver it to a new audience of the educated middle class. Changes in lifestyle during this period in Syria have had positive effect on the demand for cultural services and events. Ali's idea by buying this house was to afford each artist a room or a studio, and to transform the house into a cultural centre that encourages creativity and arts among the youth. He aimed to receive arts students and to provide grants for talented ones. Although his goals and action did not succeed due to the status of the house which was heavily deteriorated, Ali kept the house for its remarkable historical value and transformed it into his private studio (Figure 5).
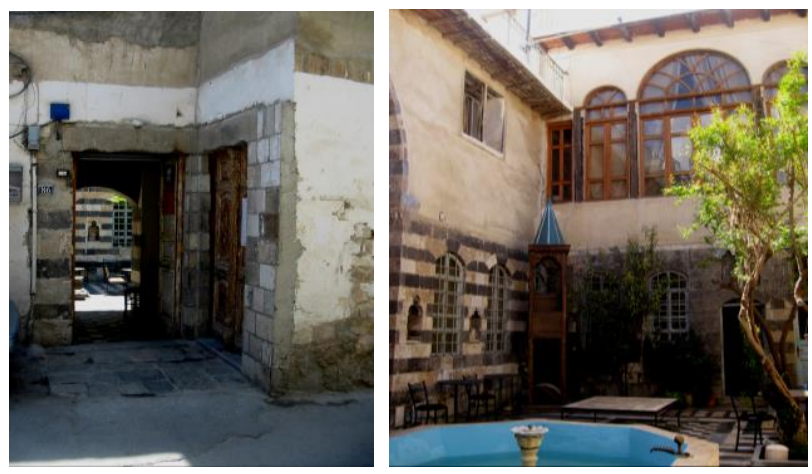

Figure 5. Studio of the artist Mustafa Ali, R.Aboukhater, April 2010.

Later, Mustafa Ali invited his friend the artist Ghassan Nana to buy a house near his studio. For him it is a chance to gather a number of artists and to further reinforce the connections of the historical context of the site with the historical quarters and monuments in the Old City. His vision was that local people and tourists will walk in the Via Recta (Medhat Pasha Street), stop at the Old Roman Arch (near the Mariamiyya Church), an important landmark in the Old City, later they can go south to visit the Artists' Quarter, then leave the district from al Qeshla Park back to the main street, the Via Recta or go straight to the north and reach Bab Touma Gate. By this, the street or the axis will turn into a cultural street that accommodates a group of studios, art galleries and exhibitions. And that is exactly what happened within a two years timeframe. Mustafa Ali moved to his house in 2004. In 2006, the Artists' Quarter was known locally and internationally. There were about 20 artists and later 30 ones, as they set a high significance in their mobility choice to a motivating and innovative cultural ambiance. 


\subsection{Vision and Transition}

The process was initiated by the Artist Mustafa Ali, but meanwhile other artists were starting to move to the place and settle in traditional houses that mostly are deteriorated or abandoned. The purpose of this gathering of many Syrian artists in the neighbourhood is to get out of isolation and to have the possibility of communication with other artists from different generations and different experiences. On the other side, it is more attractive for visitors to interact with artists while working on their pieces. This interaction, beneficial to both parties, enriches the artist's work, and gives visitors a better understanding of the Syrian art movement.

Initially there was a bottom-up strategy, but later a top-down approach to cultural regeneration started in the area. The quarter was officially known by two major events in 2007, the first one called "Seasons of Tell al-Hejara", financed by the European Union and the Italian Research and Corporation organisation with the participation of al-Makan Arts Association, founded by the artist Mustafa Ali, Goethe Institute of Damascus, and the Governorate of Damascus. The opening ceremony was organized with the presence of the Ambassador of the European Union in Syria. Brochure on this event and a map was made showing the location of artists' studios in the area (Figure 6). On each day of the event, which lasted 15 days, there was an opening of one of the ateliers, and the streets attracted a lot of visitors.

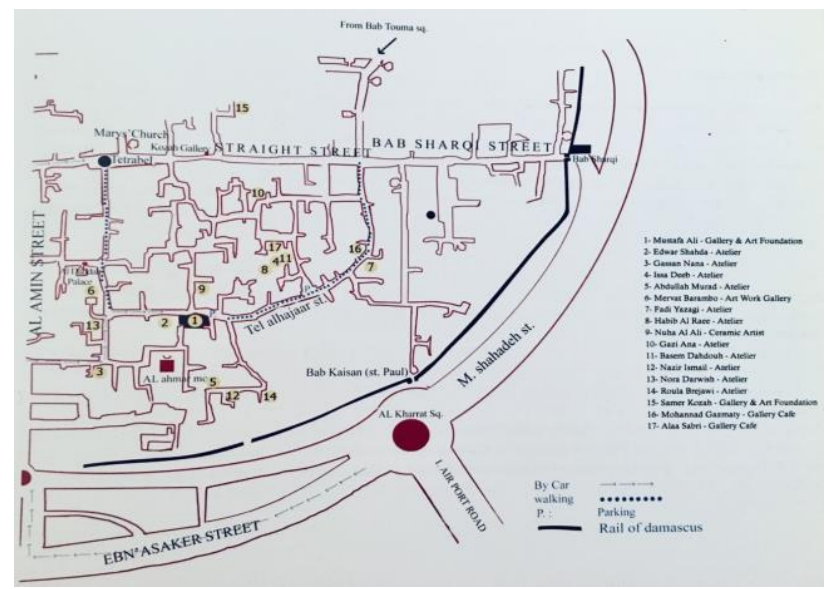

Figure 6. "Seasons of Tell al Hejara" Map, Brochure, 2007.

In 2008, in the occasion of the national celebration of Damascus as the Arab Capital of Culture, an event was organized entitled "Open Doors" when twenty studios and ateliers opened their doors for several days, attracting a lot of local and foreign journalists, to talk about this phenomenon. By 2010 , there were approximately 30 artists, some are more known than the others. The Artists' Quarter became attractive, and people who visit the Old City, pass in the district and visit the artists' galleries to meet the artists themselves (Figure 7). The continuation of this initiative is the result of collaboration between artists dedicating themselves to be a successful experience.

In October 2009, was the opening of the rehabilitation project of the nearby al Qeshla Garden at the entrance of the district from the main commercial road (the Via Recta), under the auspice of the Minister of Local Administration in the framework of the program of Municipal Administration Modernization (MAM), financed by the European Union in cooperation with the Directorate of Old Damascus.
To assure the protection and revitalization of al Qeshla Park, and to strengthen the role of the Old City as cultural destination, the (MAM) program sought to finance the rehabilitation of the shelter, located under the garden to be a suitable place for hosting art festivals and different types of artistic exhibitions. The rehabilitation project was implemented by the Order of Syrian Engineers and Architects in cooperation with the Directorate of the Old City of Damascus and the Directorate of Antiquities of the Old Damascus. The process of integrated rehabilitation of the shelter started in 2009 and included floor paving, walls painting and electric and ventilation installation to ensure that the place become ready to host events (Figure 8).

This kind of art centre in non conventional place at the Old City contributed to increase interest in cultural and historical values of the city. Early in 2010, the gallery, Rewaq al Qeshla, hosted each month an exhibition of one of the Syrian artists. The number of the attendance is between 12-30 visitors a day of young Syrians and tourists.

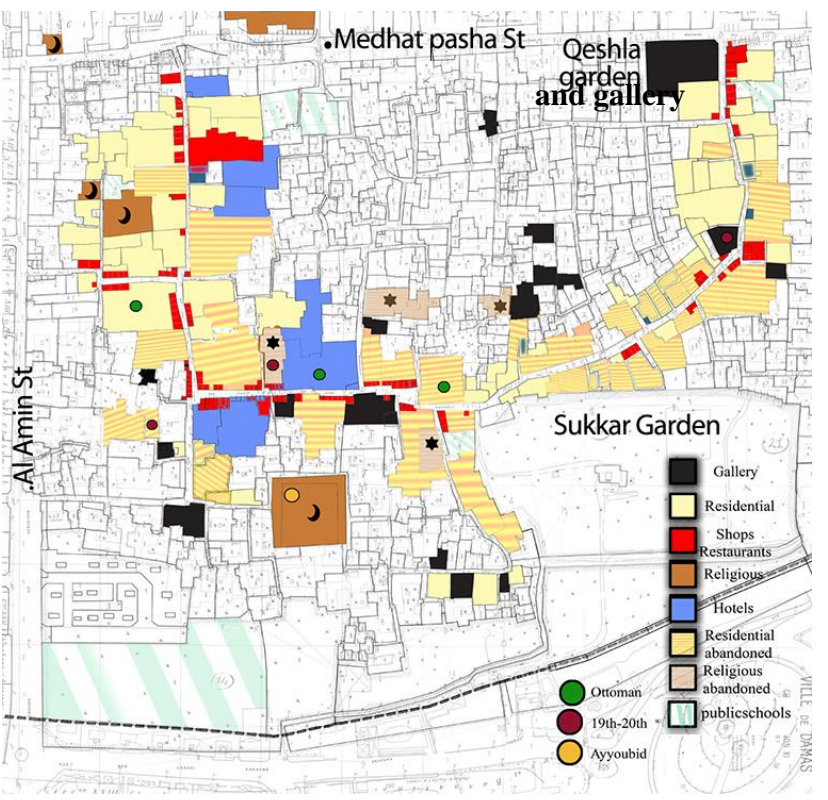

Figure 7. Function survey on the main axe at al-Amin district, R.Aboukhater and Ifpo team, 2010.
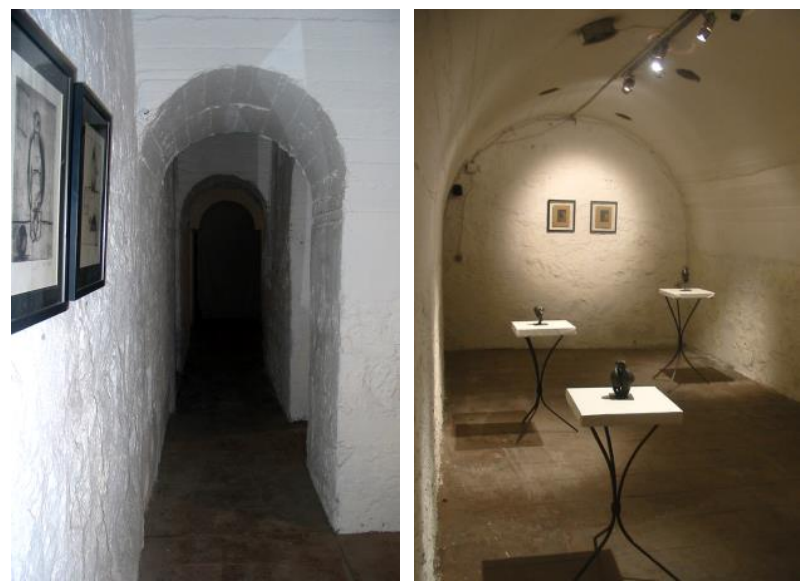

Figure 8. Interior of Rewaq al-Qeshla, R.Aboukhater, May 2010. 


\section{FINDINGS AND DISCUSSION}

\subsection{Economic and Social Changes}

There have been many economic and social changes in the district generated by the presence of artists. As mentioned by Mustafa Ali, in interview in February 2010, artists are always adventurers who occupy an area first, followed by investors immediately. Artists attract investors, visitors and tourists, and those look for several services as hotels, cafes and restaurants. The improvement of the public realm aimed to attract investments of private sector as a means of diversity of use could be crucial for long-term sustainability. "People are also taking an interest in "creative cities" that cultivate creative arts \& culture and foster an innovative economic base." (Sasaki, 2004). Several shops in the district were closed for long periods, some for eight to nine years, but as soon as the area became more attractive, many shops and some workshops of traditional crafts were opened (Figure 9). Mr. Ghassan Moawad, a shop owner, selling antique objects, in interview in April 2010, mentioned the reasons for its decision to purchase in this district, "I have chosen this place because many of my artist friends have encouraged me to invest in this area. The shop was originally selling beans and then became a women's Saloon. As a retired pharmacist from four years, I decided to exercise my hobby and passion in collecting and selling antique objects in this touristic neighbourhood".

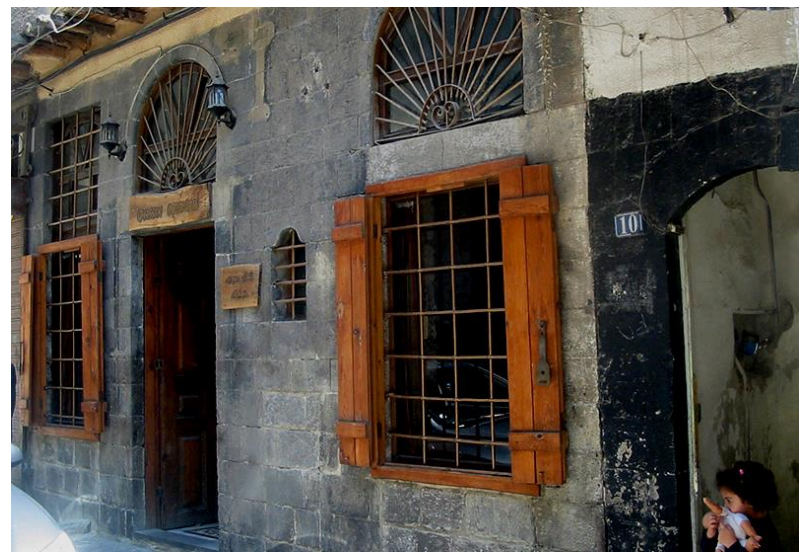

Figure 9. Antique shop, R.Aboukhater, April, 2010.

Syrian investors have been later attracted by the historical houses and palaces in the district that were abandoned and neglected, as Lizbona House or Farhi house. Usually interventions on a small scale in restoration of traditional houses could lead to a cycle of new works in many abandoned parts of the inner city to attract new businesses to the area, such as a Café-Gallery, in the district, established by a young investor interested in art (Figure 10).

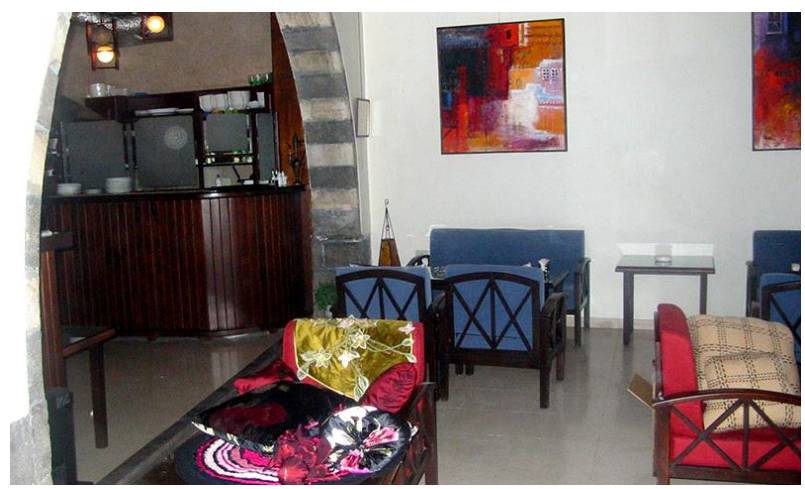

Figure 10. Café-Gallery, R.Aboukhater, May 2010.
Grodach (2008) proposes that successful culture-led regeneration relies on the distinct character or identity of the neighbourhood. The distinctiveness of the historical and the urban structure of al-Amin quarter is something very important for the success of this project; as it could not be replicated or copied exactly elsewhere. Early in 2006, Mr. Nader Kalaaji decided to purchase the Shattah House, a big and historical abandoned house, to transform it into a five stars hotel, the (Talisman Hotel) (Figure 11). It took a lot of effort and time to restore it in collaboration with the best architects in order to maintain the authentic architectural and archaeological features. About the reasons for the choice of the site, Mr. Fayez Mardini, the hotel manager explains in interview in Mars 2010, that "the district is one of the oldest neighborhoods, and many houses have a splendid decorative and architectural features, this house is about 500 years old. The district strategic location is important for us, therefore these factors have all encouraged us to choose this area specifically."

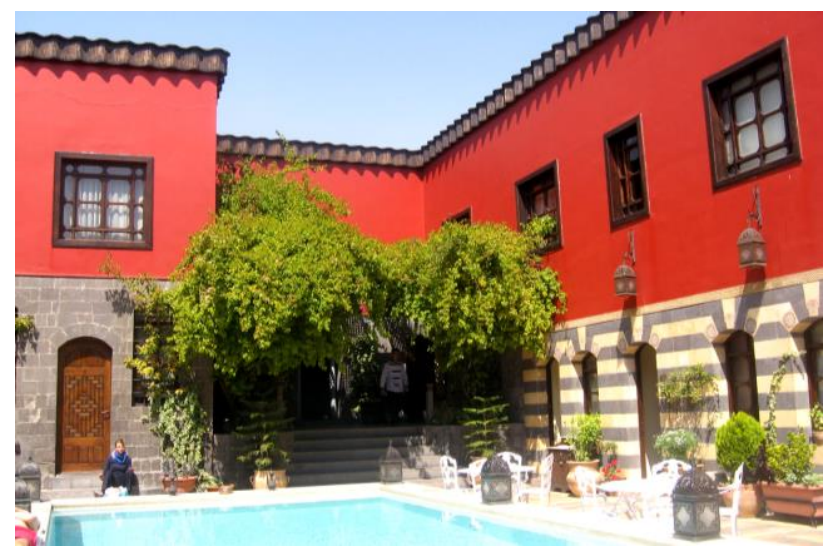

Figure 11. Courtyard of Talisman Hotel, Archive Ifpo, 2010.

The artists' studios at Tell al-Hejara Street, the main lane in the heart of al-Amin district, are mostly open permanently to visitors and tourists, as well as to the residents of the neighbourhood. Artistic workshops for children living nearby have been organized. A ceremony in coordination with the Municipality of Damascus was organized to exhibit the children's works in a small open place. The idea was very successful. Children as well as their parents were very happy. Women living nearby asked later for similar workshops for them also. This good relationship between artists and residents had a positive impact, and led to numerous joint activities, in coordination with the European Union. An Italian institution has provided support for events and festivals and has organized several activities for children in public places in the district, inviting a storyteller and a magician to present an interactive show (Figure 12). This has contributed to embrace a new social ambiance in the district.

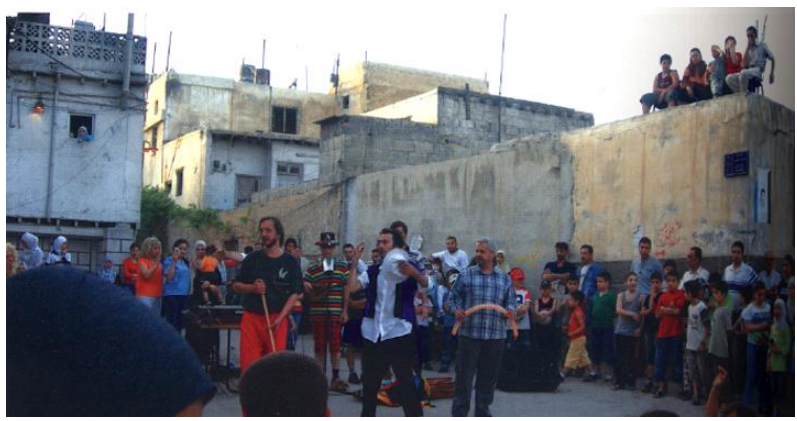

Figure 12. Event "Seasons of Tell al Hejara", Brochure, 2007. 
The designation of the artists' quarter acted as a catalyst for a number of other initiatives. A professional dancer of Capoeira, an Afro-Brazilian art that combines dance, acrobatics, and music, asked the artist Mustafa Ali for a place to practice this kind of dance. Allowing him to use the roof of his studio, first there was five persons then ten and the number continued growing until it was no longer possible to practice on the roof so he started to train the neighbourhood's young people and children in the streets and in public squares.

Arts festival and outdoor performance in public spaces have played an important role in the regeneration of the Artists' Quarter as it has contributed to the enhancement of the image of the quarter, as an arts area, and the creation of a more peoplefriendly environment for residents and visitors. Those small and medium-sized galleries and workspaces have also stimulated movement and encourage active life at the street level, participating in the revitalization of the socio-economic situation in the district. The movement on the axis at the heart of the quarter has encouraged destination outwards towards other parts of the city and so connecting it with nearby historical quarters.

\subsection{Tourism}

Most visitors to the neighbourhood, as described by residents and shop owners, were foreigners who worked in embassies and in foreign institutions. Other tourists, who came in autumn and spring, often went to the main street outside (Medhat Pacha) and did not come to this area, except in rare cases where they were interested in Syrian art.

When cultural events or professional artists activate the space, the quarter becomes a destination for tourists and for local citizens which contributes to the discovery of the rich architectural and cultural heritage of the city. Some artists also seek to revitalize the place through interaction with visitors and inviting them to his/her studio or explain some historical information about the neighbourhood.

Mr. Fayez Mardini, hotel manager of Talisman, spoke about the positive impact of the hotel in his opinion, in the interview in Mars 2010: "The presence of the hotel here has influenced the whole neighbourhood; we attract customers with high cultural levels through our participation in web sites advertising tourism. Those customers visit the art galleries and studios in the area surrounding the hotel. We have received Queen Sofia of Spain, the Aga Khan, and some actors of Hollywood (Brad Pitt and Angelina Jolie)". Those customers were keen to know Syrian artists and they visited the art galleries in the neighbourhood.

In 2008, the neighbourhood was included in the tourism map of the Old City of Damascus (Figure 13). A tourist campaign aimed to present this neighbourhood as a coherent product in the tourist promotion. Later more attention for investment in the neighbourhood has resulted in rising of prices of real estate. Luxury hotels, located in the heart of the district, have attracted customers of high levels, but without any interaction with local dwellers.

As a result of this change on the price of shops, Mr. Ghassan Mouawad, the owner of an antique shop said in the interview in May 2010 "I do not deny that there is inflation, like all areas, but there is no request on the purchase, despite the desire of many people to sell their houses here. The costs of shops in the main street (Medhat Pasha) have jumped up after the last restoration work. Things will change with the new hotel under construction in Beit Farhi."

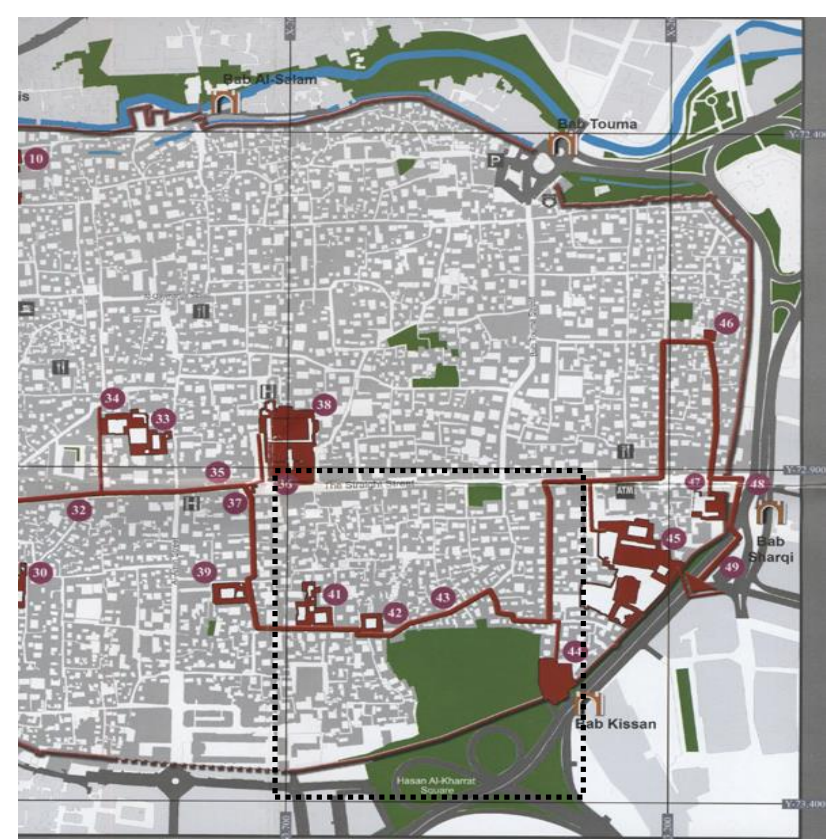

Figure 13. Itinerary in Touristic Guide, MAM, 2008.

The artist Fadi Yazigi saw some negative effects in this growing interest in tourism and had a fear of transformation of this district to be a commercial area with the increase of bad restoration of historical area. In interview in Mars 2010, he stated "Despite being with the phenomenon of gathering artists, it would be better to remain a centre of creativity and not for display for tourist",

\subsection{Spatial Changes}

Many of the houses in the district are abandoned long time ago, leaving negative environmental effects, health problems and a fear of a gradually loss of architectural and urban heritage. The bad situation of structural system of some places is due to bad restoration work. As noticed during the survey and the interviews, artists who have bought traditional houses in alAmin district had no intention to change their authenticity in term of structural or decorative features. They insist on conserving these houses that reflects their cultural and architectural identity.

The Damascene house is full of light and it is an important element for artists. The internal ambiance with the spacious courtyard, the fountain, the orange, the rose and the Jasmine trees has a positive effect on their arts and enrich their imagination and creativity. In addition, the new function as workplace, ateliers, or galleries does not need changes in the spaces or additional services. Artists have contributed to the restoration of these houses in bad physical condition with respect to conservation policies. On the other side we noticed that the restoration operations and the change of function of houses into restaurants and hotels fall outside the scope of conservation policies and turned into investment projects and negatively affected the cultural value of the site. Meanwhile, some of these projects have contributed in the enhancement of the surrounding area, of the infrastructure and the public spaces.

Before 2008 shops and restaurants were concentrated at both ends of the axis near Medhat Pasha Street, and there was no incursion deep into the neighbourhood. The return of life to the region helps returning the owners of some shops. Some 
workplaces of traditional crafts are still opened in the district, in addition to daily shops and services for the local residents (bakery, grocery, barber, etc...). Based on survey and the preliminary study by the Directorate of Old Damascus in 2006, the Detailed Guideline Plan of the Old City of Damascus was produced by the experts of the MAM project, and approved by the decision of the Ministry of Local Administration and Environment No (1655) date of 10/07/2008.

This plan defines the future designation of areas and axes in the Old City with the possibility of achieving a balance between the various activities based on the real needs and the ability of the infrastructure to accommodate the new investments and the new functions (Figure 14). As al-Amine district is officially designated as Artists' Quarter, the plan conserved its cultural designation. The report insists on preserving the historical character of Old Damascus and on preserving housing areas; as dwellers of the Old City are a vital element for its continuation. It states also the need to ensure the basic requirements and services for the continuation of their presence.

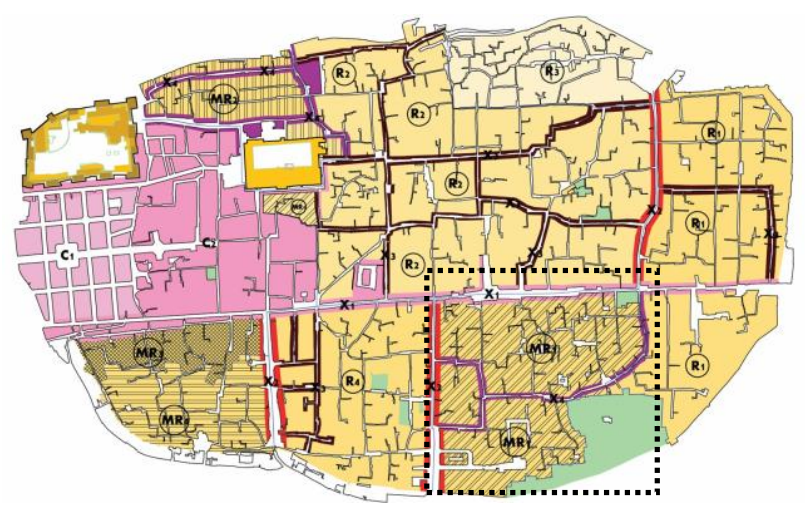

Figure 14. Detailed Guideline Plan of the Old City of Damascus, MAM project 2008. MR1: Housing with cultural and touristic functions and traditional handicrafts. X4: Cultural and touristic axe and traditional handicrafts.

\subsection{Programmed Projects}

After the success of the cultural events at al-Amin quarter, the Governorate of Damascus decided to restore several houses in the district, especially big and deteriorated ones as a first step to turn it into galleries and art centres. It decided also to improve the infrastructure, and the entrance to the Old City from al- Amin Street. In the south east area close to the artists' quarter, the Ministry of Culture had the idea of launching an international competition to design an open air theatre, art centres and cultural park at the Sukkar Fields currently an empty area partly planted by trees. The road serving these buildings could be used for official visits, and at the same time a link between Kisan Gate and the Artists' Quarter. The presence of a theatre near the district, hosting important festivals and cultural events may have benefits for the whole district. But the project had not been realized.

The artist Fadi Yazigi expressed, in interview in Mars 2010, his rejection to the idea of creating a theatre in the nearby fields from an environmental point of view "it should not be converted into a theatre, it should remain as natural fields, as a lung to Damascus, not even turns it into a public garden, it should be protected as it is".
There were different points of views of artists about future projects in the neighbourhood; some are hoping to give more attention to tourism. But others hope it become a place of culture that could help in the recognition of Syrian art in general and in raising awareness of the importance of the cultural heritage of the neighbourhood. There is a need to ensure good infrastructure (roads, drainage system...) and to focus on the renovation of the large percentage of abandoned houses to be workplaces for artists and rented at a low price. They prefer it to be a district of artists, a centre of excellence different from other nearby historical neighbourhoods where there is abundant number of restaurants and hotels.

\subsection{Situation after 2011}

As the situation got complicated in Syria with the escalating violence, the local and international interest in cultural and urban development of the district and the Old City was put on stand-by. Consequently, only six artists stayed during this period, those are the founders of the Artists' Quarter. Their studios were opened for visitors and some events happened during the time of war. On the other side, many young Syrian artists have left and their studios at al-Amin district were closed.

The gallery of Mustafa Ali continued to host cultural activities in the neighbourhood in collaboration with other Syrian NGOs without interruption during the war. It became a place to escape the war in the city, a hope generator for the Syrians. Since 2016, activities began returning gradually in the district. Several events were organised at the Gallery. Artists have had the possibility to exhibit their works during this hard period (Figure 15).

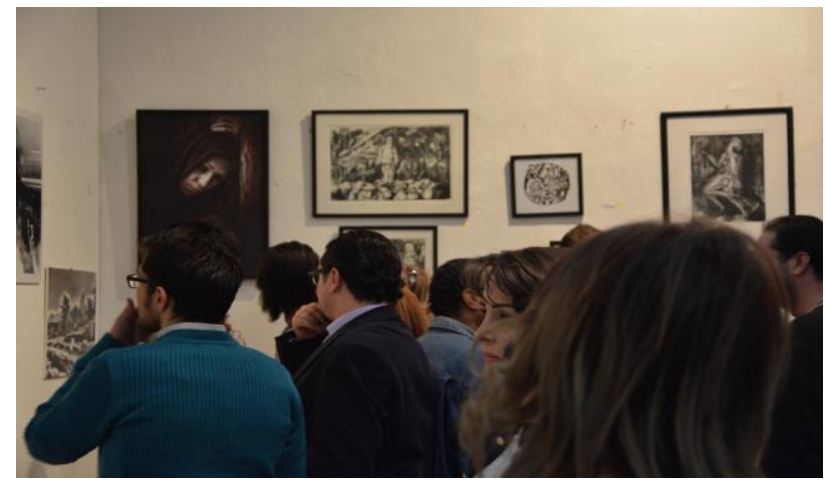

Figure 15. Exhibition Mars 2016, Mustafa Ali Gallery Archive.

Activities varied from art exhibition to music concert, theatrical spectacle and cultural debates. Every Saturday, local dwellers especially children could participate and learned several skills through several training and artistic activities (Figure 16).

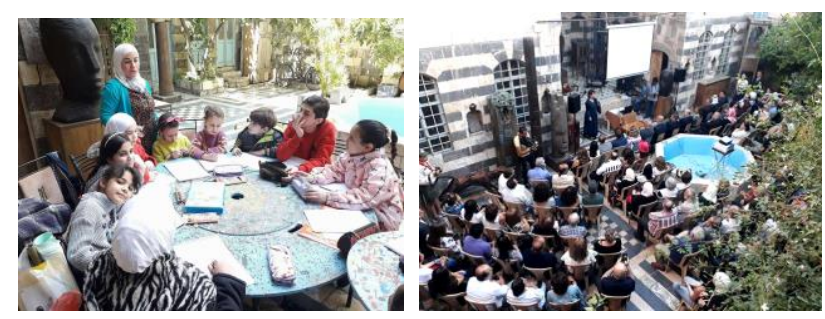

Figure 16. Varied activities in 2018 (left) and in 2019 (right), Mustafa Ali Gallery Archive. 
Many restaurants and cafes closed their doors due to the decreased number of tourists and visitors. Almost all hotels were closed, or rented by Syrian immigrants from other parts of Syria. The five stars hotel Talisman has launched a new image during the month of Ramadan 2019, at present, it is working more as a Café - Bar hosting music concerts and spectacles. The pursuit and survival of those cultural spaces and events in the Old City could participate in the preservation of the cultural and architectural heritage of the neighbourhood.

\section{CONCLUSIONS}

The research here revealed that the choice of location for the establishment of studios and galleries was due mainly to the low prices of houses compared to other areas within the Old City. At the same time, artists aspire to get a place near the city centre or within the Old City. This approach indicated spontaneous and a bottom-up process. It was not built on the nature of activity that already existed in the area. It was forced by the artists of other places looking for workplace in the city.

This gathering allowed artists to obtain a unique experience through their presence in traditional houses with rich decoration and architectural details in addition to the presence of plants and water in one place in the heart of the Old City, which helps in creating an atmosphere suitable for artistic creativity. This has also encouraged some artists to return to work in art and to benefit by being part of the collective framework that links the artists. This situation allows dialogue and creative competition between artists, pushing forward artistic production.

The district has started to shift from a residential district to a cultural and touristic district with a special character. It became an element of attraction, especially for artists (local and global) and helped to set the area on the map after the increased attention to tourism and the provision of touristic services in the neighbourhood. These changes have helped to increase the number of passers-by and thus reduced the sense of isolation in the alleys and increase safety. Visitors are interested in meeting Syrian artists during their work as the neighbourhood is a place essentially for production in studios and not a place for display.

In order to measure the extent to which culture was identified as a catalyst in the regeneration process, it is argued that the initial cultural hub of the artists' studios and the cultural activities would have led to the regeneration of this area and certainly that the development required mixed use facilities to include a balanced and broader process of economic development. Culture can act as a generator for economic activity and driver of investment; as cultural area can attract people who will use non-cultural facilities such as cafes, restaurants and hotels. The investment in hotels and opening of new shops are evidences of the capacity of culture to produce economic impacts through private investment or governmental development projects. It is the result of the effect of culture, in attracting new creative projects, the "butterfly effect". Creating this mix of uses in an area helps to support each other and to raise confidence in the area and transform it to a liveable place.

The development of comprehensive study should take into account social factors and the diversity of the population in this district as well as integration of spatial development with economic development for the benefit of the residents. That could increase interest in the neighbourhood and brought recognition to its architectural and urban values, especially by residents whom were unaware of the historical importance of the district.
In this regard more attention in protection and restoration of architectural heritage contributes in reviving the unique identity of the place and helps to attract interested developers on one hand and a feeling of pride of residents in their heritage on another. One of the key findings is that heritage management based on promoting creative and cultural activities could play a major role in developing declined historical areas.

A real concern in urban development cases based on culture-led approaches is in relation to inclusion and involvement of the community. Some cases can encourage social cohesion, but they can also lead to the exclusion of resident and community groups through the process of gentrification (Roodhouse 2006). A large number of the population at al-Amin district do not accept this phenomenon and they consider it a violation to their privacy and their daily life. Residents feel isolated as some of these places are opens only to special groups of high economic or cultural level. The main lane, Tell al-Hejara has been transformed to a first-class touristic area. Working with the local community through participatory process and involving various relevant groups and stakeholders may enable the integration of the local community in the development process.

\section{ACKNOWLEDGEMENTS}

Special thanks to the team of the Project "Cultural Participation for Heritage Regeneration" at the Institut français du ProcheOrient (Ifpo), especially to Z. Fallah and N.H. Souri for their participation and support in conducting the interviews and the survey of al-Amin district in 2010.

\section{REFERENCES}

Dungey, J., 2004. Overview: arts, culture and the local economy. Local Economy, 19(14), 411-413.

Grodach, C., 2008. Museums as urban catalysts: the role of urban design in cultural development. Journal of Urban Design, 13(2), 195-212.

Montgomery, J., 2003. Cultural quarters as mechanisms for urban regeneration: conceptualising cultural quarters. Planning Practice and Research, 18(2), 293-306.

Roodhouse, S., 2006. Cultural Quarters Principles and Practices. Intelligent Books. Bristol.

Sack, D., 1989, Damascus: Entwicklung und Structur einer Orientalisch-Islmischen Stadt. von Zabern.

Sasaki, M., 2004. The Role of Culture in Urban Regeneration Diàlegs, Fòrum Universal de les Cultures, Barcelona. 